Int. J. Electrochem. Sci., 15 (2020) 1742 - 1756

International Journal of

ELECTROCHEMICAL

SCIENCE

$\underline{\text { www.electrochemsci.org }}$

\title{
Polyaniline/Ba bismuthate Nanobelts for Sensitive Electrochemical Detection of Tartaric Acid
}

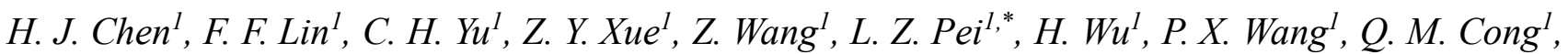 \\ C. G. Fan ${ }^{1}$, and X. Z. Ling $^{2,3, *}$ \\ ${ }^{1}$ School of Materials Science and Engineering, Anhui University of Technology, Ma'anshan, Anhui \\ 243002, P. R. China \\ ${ }^{2}$ School of Civil Engineering, Harbin Institute of Technology, Heilongjiang, Harbin 150090, P. R. \\ China \\ ${ }^{3}$ School of Civil Engineering, Qingdao Technological University, Shandong, Qingdao 266520, P. R. \\ China \\ *E-mail: lzpei1977@163.com (L.Z.Pei), ling_xianzhang@163.com (X. Z. Ling),
}

doi: $10.20964 / 2020.02 .55$

Received: 1 October 2019 / Accepted: 1 December 2019 / Published: 31 December 2019

An in-situ polymerization route has been applied to obtain polyaniline/Ba bismuthate nanobelt $(\mathrm{PAn} / \mathrm{BBN})$ composites with different polyaniline mass percentage. The PAn/BBN composites were characterized by X-ray diffraction (XRD), transmission electron microscopy (TEM), high-resolution TEM (HRTEM) and electrochemical cyclic voltammetry (CV) method. XRD shows that the obtained composites are composed of monoclinic $\mathrm{BaBiO}_{2.5}$ phase. Transmission electron microscopy observations show that the amorphous polyaniline particles with the size of less than $100 \mathrm{~nm}$ attach to the surface of the $\mathrm{Ba}$ bismuthate nanobelts. The PAn/BBN composites modified glassy carbon electrode (GCE) exhibits good electro-catalytic activity toward tartaric acid (TA). A pair of quasireversible $\mathrm{CV}$ peaks are located at $-0.69 \mathrm{~V}$ and $+0.49 \mathrm{~V}$, respectively. The negative shift and increase in the current show that the PAn/BBN composites modified GCE has enhanced electro-catalytic activity toward TA. The influence of the scan rate and electrolyte on the electrochemical responses has also been researched. The limit of detection (LOD) decreases from $0.12 \mu \mathrm{M}$ to $0.08 \mu \mathrm{M}$ with increasing the polyaniline mass percentage from $10 \%$ to $40 \%$. The PAn/BBN composites modified GCE shows good stability and reproducibility.

Keywords: Ba bismuthate nanobelts, Polyaniline, Transmission electron microscopy, Electrochemical detection, Tartaric acid. 
(C) 2020 The Authors. Published by ESG (www.electrochemsci.org). This article is an open access article distributed under the terms and conditions of the Creative Commons Attribution license (http://creativecommons.org/licenses/by/4.0/). 